\title{
Congenital dyserythropoietic anemia type II
}

INSERM

\section{Source}

INSERM. (1999). Orphanet: an online rare disease and orphan drug data base. Congenital dyserythropoietic anemia type II. ORPHA:98873

Congenital dyserythropoietic anemia type II (CDA II) is the most common form of CDA (see this term) characterized by anemia, jaundice and splenomegaly and often leading to liver iron overload and gallstones. 